\title{
DISCUSSION ON CLASSIFICATION OF NEUROLOGICAL LESIONS
}

OPENER: Michaelis, L. S. (Switzerland). This is a subject for thought, and when I tried to do that it occurred to me first of all to investigate how far, when we talk about neurological lesions and when we write papers about them, we have made sure that we are talking about the same thing. Therefore, I wrote to a number of Centres and in addition to a few neurosurgeons and asked them what were their methods of classifying the level of the spinal cord lesion. I found that the method used in Stoke Mandeville, as well as in the other great Centre in Long Beach by Dr. Bors, to classify a case according to the last intact segment of the cord, is used by about only two-fifths of the Centres. For instance we say this is an incomplete transverse spinal cord syndrome below $\mathrm{C}_{5}$. In addition, here and at Long Beach, level and peculiarities of the fracture or fracture dislocation of the spine is given separately. Almost three-fifths of the continental centres use a method which appears to have arisen from the great French school of neurology in which the first affected segment is taken as the level. They do not say complete or incomplete below $\mathrm{C}_{5}$ but they say complete or incomplete C6. However, just at this level you will realise that the difference in classification for the patient and for our understanding of his problem is quite considerable. There is a third method, namely to classify the lesion according to the damaged vertebra. This method is, however, only used by two Centres, curiously enough one in Britain and the other in Switzerland. I must say that I greatly regret that these two important Centres still use a method which has very little use, particularly in distal lesions of the cord. We all know that a fracture dislocation of $\mathrm{T}_{12}$ or Tio can produce a complete or incomplete lesion of the cord below $\mathrm{T}_{9}$ or a cauda equina lesion below $\mathrm{L}_{3}$ or $\mathrm{L}_{4}$. This example shows that to classify a neurological lesion according to orthopaedic principles is certainly not the right way.

Now what can we do about the fact that these three different systems exist? We cannot ask old-established Centres to change their methods. I would suggest two things: Firstly, that every paper published where the neurological level plays an important part should make clear which method of classification is used. Then we shall know where we are. Secondly, new centres should, if possible, adopt one of the two neurological methods of classification mentioned above. I, personally, naturally have a preference for the one used at Stoke Mandeville. I think it is more precise and I would suggest that those who will be in charge of new centres should introduce that method.

The second question in my first enquiry form concerned the ways in which we assessed muscular strength in incomplete and recovering lesions. There exists the British system, the M.R.C. system, and there exists a system which was developed in the Mayo Clinic, and there exist others. I am glad to say that the overwhelming majority of Centres are using the British system, and I am quite certain that it is preferable to the others, not only because it is already in use by most but because it makes it possible for observers to learn, to assess the varying degrees from five, i.e. full power, downwards to nothing in a systematic way. Everyone who is in charge of paraplegics and tetraplegics should take some good time to learn the techniques 
and to try and get a precise assessment both for himself and comparable with that of others.

The third question of the enquiry concerned the ways in which we try to subclassify incomplete lesions. Most answers which I have received so far give exact description of the lesion. This is very good, and every individual phase should have an exact description of the lesion. The difficulty comes when you try to write a paper about a certain subject in which you want to group people. As you know, the range of incomplete is very large. The Long Beach Centre has worked out a fairly clear system of subdivisions which is probably applicable to most of the cases we want to describe. If we can make up our minds that we make quite clear what system of classification we adopt I think we shall increase the comparability of our results.

The second enquiry form attempted to give an indication when to make a firm prognosis in an individual case, particularly during the early stages. The practical importance of that is this; first of all it must be admitted that sometimes we have been proved wrong by saying something too early to the patient, or to relatives, colleagues, or, particularly, in reports to insurance companies. It might be a good thing to get guidance on what might be, collectively termed, the right time. Now, the answers to this particular question have been staggeringly different. There are quite a number of people who insist that in a complete lesion at any level they will decide after 24 hours whether that is going to stay complete or not. On the other hand, there are those who will in no case make a firm prognosis before six months after injury. I, myself, am inclined to think that in complete lesions in paraplegia the right time lies at three weeks at the end of spinal shock, and that in tetraplegia one ought to wait longer, up to six weeks, because we have seen significant late recoveries. I am not now talking about a few sensory levels at the end of six weeks. In incomplete lesions-and that is where my questionnaire was over-compressed, and quite a number of kind people complained that I had not expressed that properly-how long has one to wait until one can be pretty certain how much further recovery one can expect? I believe that the various degrees of incompleteness, the time of observation, the times the neurological examinations have been done by oneself are very important. But one cannot generalise and I hope to work that out and analyse it when the whole thing comes to publication.

And, lastly I asked a few questions on comparatively rare conditions, for instance, has anyone ever seen in a completely paralysed muscle recovery taking place more than two years after the accident ? There, a few positive answers have arrived, but you may agree that up to now on the whole it was said that what is not there by two years will not come later. I shall try to analyse the answers and bring this before you again.

I should like now to bring up another point. It occurred to me that new centres and particularly new small centres are at a great disadvantage in collecting experience, particularly in rarer fields of our work. I am inclined to think that systematic collaboration between these centres is one of the solutions. In Basle, we are geographically very nicely situated, and I am lucky enough to have friends in not too far distances-in Heidelberg, in Mulhouse, in Geneva, and soon in Murnau. We propose to pool our resources, to distribute our research and to correlate what we are trying to do and to avoid unnecessary overlap in our projects. We may help each other with material, and therefore might be able to catch up a little sooner with those long established centres who have given the lead to all of us. 
Finally, in connection with what I said the other day, it looks as if among ourselves we are seeing perhaps only one third of the paraplegics and tetraplegics that occur in our respective countries. It means we do not know how often traumatic and non-traumatic paraplegia and tetraplegia occur. Would it be possible to improve on that? I feel Switzerland, as a small and highly organised country, might give a lead in this respect. At my suggestion, an attempt is being made by one of the big insurance companies with the help of a young man who is trying to write a paper on statistical matters, to find out how many paraplegics there really were in Switzerland since 1960. Results are not yet finished, but one thing is quite certain. The old accepted ratio of one paraplegic per hundred thousand is already too small; it is at least one and a half paraplegic per hundred thousand. We shall in this way perhaps be able to establish a pattern of statistics which might be applicable to other countries. I have even thought whether it might not be possible to louk at paraplegia at this stage in an epidemiological way and try to make paraplegia a notifiable condition-notifiable either to a government or to an insurance company or to a central body-I am quite certain that one would learn from such an approach a good deal.

Sir Ludwig Guttmann (G.B.). Thank you, Dr. Michaelis, for this preliminary report. I think it is an important one and we might, in due course, achieve some uniformity in expressing what we are really doing. You have heard about the great discrepancies of opinion which still exist in the field of classification, and it was an excellent idea to bring the matter up for a preliminary discussion. It will take some time, of course, to develop the whole problem further.

\section{Discussion}

Hardy, A. G. (G.B.). I enjoyed Dr. Michaelis's remarks; I knew something about them beforehand and I welcome very much his idea to collect all the information to see in what forms our diagnoses are made and how they are recorded. He said, you cannot ask old established centres to change their systems. Some of us can, and although I have made some of these recordings for I 500 cases that does not mean to say that I cannot look at them and analyse a paper like Michaelis's and improve our own means of classification. I think that is quite wrong and I would like to say to Dr. Michaelis some of us can change.

The second point I would like to raise is again this question of qualification, and I am sure we are getting to the stage when we have got to say how complete is complete and how incomplete is incomplete, and I hope that very soon we shall all be able to compare like with like.

Harris, P. (G.B.). I had the opportunity of completing one of Dr. Michaelis's questionnaires and entirely agree with Dr. Michaelis, and I also agree with Dr. Hardy and I think that we can change. There is a problem here. When you come to define your cases from various points of view, such as has been done in Edinburgh, and when you begin to put your material together suitable for computers, you must make up your mind and you cannot delay too long. I would suggest, therefore, Mr. Chairman, that there is some urgency in this matter, and we should all of us here help Dr. Michaelis as much as possible.

There is another point I would like to mention, the idea of making paraplegia in some way notifiable. This has occurred to me, also, and I put it to the authorities in Scotland some time ago; they are thinking about it.

The third point is the international classification of disease. There is a book on this subject which is revised every ten years. I have tried to find out who is involved in its revision, because really it is a useless document, useless entirely for our purposes. I 
would like the support of the Society, to try and do something about this, because the classifications are so out of date and cannot be used.

Paeslack, $V$. (Germany). In the German speaking centres we have for the classification of the spinal cord lesions one special difficulty, because for instance some of us use the term 'Laesion ab $\mathrm{T}_{7}$ ' and 'ab' can mean two things, 'below' and 'including' $\mathrm{T}_{7}$. So, I think for the German speaking institutions we have to define it more precisely and indeed have to write from now on if we want to take over the Stoke Mandeville terminology, 'unterhalb $\mathrm{T}_{7}$ ', i.e. below $\mathrm{T} 7$ and cannot use any longer the word ' $\mathrm{ab}$ '.

With regard to the use of the book of the international classification. I agree this is for the question we are discussing here absolutely useless. But, if we are going into the problem of a general documentation and classification we have to distinguish two things; the first is the basic documentation, as used on the front paper of our notes. I feel we have to use an internationally agreed classification, but for a more detailed documentation we need classification and terms that are specific for paraplegia or spinal injuries. So, in Germany we are at the moment starting a new classification system for the whole medicine that is in correlation with the international classification. The difficulty with the international classification is that it was made as a key for mortality, not for diagnostic purposes, and there are large parts of medicine not in it. The new German classification that came out six months ago is definitely better, as it considers all parts of medicine from a diagnostic point of view. But, it is still not satisfactory for our own purposes and so we have started work on making classification keys for all the details of paraplegia and its complications. This is a job which cannot be done in the next few months but will need, I think, three or four years. In the meantime, we have to collect the data and I think the proposal which Dr. Michaelis has made in his first Basle documentation is good but it is not detailed enough to make a real documentation and classification for the computer.

Maglio, $A$. (Italy). I hope that in a few years we will be able to speak the same language in the classification of spinal cord damages. I used in my Unit, from the beginning, to distinguish always between the level of the fracture and the neurological level. This is necessary for the official documentation in the ward. It is the neurological level that is the basis of all training, of all treatment and work of my staff. In incomplete lesions we also describe the conditions under the neurological level. This is more difficult for my staff but I think with this system at present one can diagnose the exact condition of the cord after injury following fracture of the spine.

Meinecke, F. W. (Germany). I cannot agree with Dr. Paeslack. We distinguish in Germany, as others do, between at and below. The German word 'ab' means exactly 'at', and the word 'unterhalb' means exactly 'below'.

Paeslack, V. (Germany). You may be right, but in fact I found very often in the diagnosis even of our neurological colleagues that some of them use the word 'ab' meaning including, and some 'excluding', and it is not absolutely clear what it means, also not in the general German language.

Wolman, L. (G.B.). May I congratulate Dr. Michaelis on a lot of hard work and hard thinking, which he has carried out since he went to Switzerland. I would like to put in a plea from the pathologist's point of view, about these levels. Dr. Michaelis quoted the lumbar spine injury where the neurological level could vary from, I think it was $T_{9}$ he said down to $\mathrm{L}_{3}$. To talk about a neurological level at these particular segments of the cord could imply that the bony injury could be anywhere in the lower thoracic or lumbosacral segments, and it seems wrong to the pathologist who has got to try and correlate the neurological findings or orthopaedic findings with the histological findings not to include a bone level when the neurological level is so variable from so high up to so low down. That was the first point.

The other point is that from the pathology point of view I am very much against, though I admit the clinician has to do this, saying that the level is either at or below a particular level. This, I think, to my mind, makes people think of your spinal cord lesion 
rather naively as being an almost sort of knife blade transection of the cord. Now, I think we all know that in actual fact when you come to look at the histology of the cord, at and above and below the damaged segments, none of these lesions are purely transverse. I think that one can liken them to perhaps one or two segments of maximal damage and then a sort of tapering cone upwards, rather like a dunce's hat, and a tapering cone downwards. And, when I do the histology on these cases for Dr. Hardy I really bring in three factors in talking about any particular lesion: firstly, the bony level of fracture or fracture dislocation at say $\mathrm{C}_{5}$, C6 or whatever is involved, spinal cord damage maximal at say one particular or two particular segments, $\mathrm{C}_{5}$ or $\mathrm{C}_{4} / 5$, but a lesion extending upwards, giving its uppermost extent, which might be $\mathrm{C}_{2}$ or $\mathrm{C}_{3}$, and its lowermost extent. So that the three things from the pathologist's point of view, I consider first the level of the bony injury, secondly the cord maximal damage and thirdly the vertical and extent of the damage both upwards and downwards.

Sir Ludwig Guttmann (G.B.). I think I have to make one remark to Dr. Wolman. I do not feel clinicians are really as naive as he thinks. It is now general knowledge amongst clinicians concerned with spinal injuries, of the discrepancy which exists between the level of the vertebral injury and the level of the cord damage, whether complete or incomplete. That is the reason why, as Dr. Michaelis pointed out, a clear distinction must be made in the classification. Furthermore, it is also general knowledge amongst clinicians, especially neurologists, that the traumatic pathology of the spinal cord is as a rule, apart from certain stab wounds, hardly ever a knife blade transection of the cord. The horizontal or transverse damage is often associated with vertical damage of varying degree above and below the transection which can be classified by thorough clinical examination and should be a guide for the pathologist.

Walsh, F. F. (G.B.). For many years we have been criticising our Ministry in this country because they have not available the figures of paraplegia, and I was very embarrassed recently to go to a Regional Board and be told but of course they are available and have always been available and this is in a publication which is produced every couple of years-I think it is called 'The Analysis of Inpatient Bed Occupancy'. It is, in fact, at the moment available in the back of the Platt Report in this country. One of the categories they give there is 'Spinal Injury where there has been neurological involvement'. Now, there may be a few cases beyond paraplegia, but it will be at least a rough guide, and I think to the Ministry's surprise they found that this figure is very steady at the moment400 to 500 per year from England and Wales. With regard to that, it may be that other countries, although it is not a notifiable disease, may have these figures available in some particular paper. The second point is what I think Dr. Paeslack said a while ago, the necessity for having a really accurate assessment on the very first page of the notes. This does not apply quite so much to Spinal Injuries Centres but it does apply to general hospitals, in many of which, as pointed out by Hardy to me yesterday, the extraction is done by a clerk who puts down whatever is on the first page. If this is right you have good records, if it is not right you have very bad records.

Sir Ludwig Guttmann (G.B.). Dr. Walsh will remember when we had, I think, three years ago, a Symposium on wheel chairs, we were presented with a statistic from the Ministry regarding wheel-chair users. I found that spinal injuries were only 0.5 or 0.6 per cent. However, if one added (which was not done by the speaker who presented the statistics) those non-traumatic cases, classified as 'neurological lesions' which included polio, tumours of the cord, transverse myelitis, spina bifida etc., it was no less than over 25 per cent. of all wheel-chair users. Therefore, national statistics should distinguish between the various causes of spinal cord lesions to give an overall clear picture about the incidence of spinal paraplegia and tetraplegia of all causes.

Frankel, H. L. (G.B.). I would like to ask Dr. Michaelis about the results of using this mechanism of collecting information, writing to his friends all over the world with 
little forms. How many reply, how quickly do they send their answers, how many cross out the questions and put their own in and similar events?

Michaelis, L. S. (Switzerland). I thank all colleagues and friends who have answered my enquiry and I am most grateful. In answer to Hans Frankel, the replies are over 80 per cent. so far and several more have been promised, so I am hopeful that I shall really get a complete set of replies. Now, one purpose of my sending out this enquiry was to make quite sure that it is universally recognised within and without our Society that the neurological examination is the basis of all we do. I talk to you as somebody who until the age of about 48 was as innocent of spinal neurology as one can possibly be. And, nothing has given me a greater pleasure than to be torn to shreds by our President during those years when he still had time to let us come before him with a new case examined, read out by us and then hearing how things really were. And, I can tell you that it took me a few years until I emerged from this ordeal in one piece. It is the most important thing in the career of all of us that we first of all learn to use the tools of our trade. Our trade may be or may have been previously urological, orthopaedic, accident surgery or rehabilitation, but unless the Head of a Department in our field becomes an experienced spinal neurologist we will not have a good Unit.

I must come back to the point made by Mr. Harris. The computerising of our results will be our duty. It is a modern technique and my mathematical gifts have been limited from the beginning and I do not think they are going to improve from now on. This deficiency on my part suggests to me something which I would, in all modesty, suggest to the President and the Council of the Society. It is, perhaps, worth while to set up a Standing Working Party composed of experienced members of this Society to prepare, internationally, notes that can be computerised. We can merge two jobs into one. We can suggest the most commendable way of neurological classification and we can at the same time devise sets of notes which will be just as reliable in French, German, Italian, Spanish etc. as they are in English. We have seen amongst ourselves about 40,000 paraplegics. Now, before that becomes 400,000 we ought to know exactly what we are doing and we ought to be able to compare our work from all parts of the world. This suggestion I would like to leave with you.

Garcia, H.R. (Spain). In relation to the terms complete or incomplete paraplegia, I must say that some problems arise from the use of these terms. Paraplegia in my opinion is a functional term and means that there is a complete palsy of both legs which abolishes walking or standing without orthopaedic aids. If standing or walking is possible in a partial paralysis, we must say paraparesis. In a low lesion-cauda equina or a conus medularis lesion - we should not say paraplegia below L2 but a cauda equina or conus medullaris lesion with complete paraplegia or paraparesis. This, I think, is the correct way of expression.

Rossier, A. (Switzerland). About the question of proportion of new spinal cord patients pro year and pro million inhabitants. It is perfectly correct what Dr. Michaelis said, but we must not forget that this work, a most consistent work about these effects, has been made by Maudot, a French doctor in 1954, and from that time on it has always been accepted in Europe, in the States, Canada, England, France, etc., that the ratio of paraplegia was from about six to eight new cases per year per million inhabitants. This was in 1954, and now we are quite sure that these figures have changed and must be between Io and I 5 per year per million inhabitants.

Barry, B. O. (Ethiopia). I was very glad that in that very important questionnaire of Dr. Michaelis's he has tacked on this investigation of a fallacy of the two year rule. I have had in Ethiopia to fight this very repeatedly, not so much I must confess in paraplegia as in polio. It pre-supposes that there has been active and complete treatment of the patient during those two years, and most of my cases, especially in polio, are after the two year period. My colleagues immediately quote this and say do not waste your time, there is nothing more to do. I would suspect that in a paraplegia as well there is the same 
pre-supposition and that the levels and variations in treatment which are given may be reflected in some of the answers Dr. Michaelis may have had.

Paeslack V. (Germany). May I ask Dr. Michaelis whether his statistics also included children with spinal dysplasia?

Michaelis, L. S. (Switzerland). No.

Sir Ludwig Guttmann (G.B.). In summarising the lively discussion we have had, I feel also I should give some guidance for the future work. First of all, Dr. Michaelis has done an excellent work to start off this important subject and I think he should continue to collect material himself. I think it is too early to set up a special committee, and Dr. Michaelis will have, I hope, the support of all colleagues. Perhaps in a year's time or so we could get together and discuss again what has been collected. This kind of thing cannot be rushed and has to be done very thoroughly.

I entirely agree that the international classification is quite unsatisfactory. But, I think we can make one clear statement: a spinal cord injury is a neurological lesion and whatever the cause, whether it is due to a fracture, tumour, vascular etc., the level of the lesion should be classified as segmental and in cauda equina lesions according to the spinal roots involved. I hope that workers in the field who are not very familiar with neurology, in particular general surgeons, orthopaedic surgeons and urologists, will accept this idea to make the clinical diagnosis of traumatic lesions of the spinal cord in accordance with the segments of the spinal cord in addition to the level of the damage of the vertebra. With regard to the distinction between 'at' and 'below' the level, I still feel that the most logical and most simple clinical diagnosis is to classify a lesion below the last functionally normal segment. One has to distinguish if possible, immediately between a physiologically complete and an incomplete lesion. That does not mean, of course, that the first diagnosis and assessment is final. Moreover, in a complete transverse spinal cord syndrome one has to find out the additional vertical (longitudinal) damage which may have occurred above and below the transverse lesion. To use the expression maximal damage, as suggested by Dr. Wolman, would only add to the confusion which already existed in the terminology. We are in a position to classify a cord lesion as complete whether it is actually due to an anatomical transection or produced by a lesion in continuity.

In differentiating the muscular damage we have also to be very exact. We can distinguish precisely which muscles of the segment or segments involved are completely interrupted and those which are only partially damaged. This can be distinguished by functional tests, including electrical examination of the individual muscles. I do feel that the British system of assessing the muscular damage is logical and a good one, and I suggest it should be continued. With regard to the question what is 'incomplete' and what is 'complete', raised by Dr. Hardy, there is indeed confusion, particularly in the expression 'incomplete'. Some people distinguish between 'incomplete', 'partial' and 'sub-total'. Sub-total and partial lesions are, of course, 'incomplete'! We must not introduce too many sub-classifications, that would rather add to than lessen the confusion.

Hand in hand with the muscular assessment goes the reflexological assessment, and in particular time and localisation of reflex return after spinal shock has subsided must be properly recorded. This is also of great importance for the diagnosis of vertical damage in complete transverse lesions. With regard to the sensory function, there are, of course, enormous varieties of disturbances which must be recorded properly, both qualitatively and segmentally, from the beginning and throughout all phases, because only then can we establish a proper relationship between the clinical picture and the neuropathological findings later.

In addition, we have the various types of dysfunction of internal organs, especially the bladder but also the bowels and sexual function. All this must be put in the notes from the beginning and followed up. You will, therefore, understand why I mentioned previously that it will take some time until classifications can be made acceptable to everyone, let alone the difficulties in computerising clinical data. 
A very important point has been brought up by Professor Barry-the question whether or not a muscular paralysis can improve after two years. In all my teaching, I have been strongly opposed to the dogmatic view-and this applies in particular to polio and peripheral nerve lesions - that if after two years no recovery has occurred one should give up treatment. I think this is a serious mistake sometimes made by both surgeons and neurologists alike. I have seen so many patients who were given up after two years and yet made substantial muscular recovery after that period. This applies both to lesions of the lower motor neurone and also to sensibility.

Finally, the question of notifiability. I agree entirely with Harris and Michaelis-it would be a wonderful thing if the Government Department responsible were to ask that paraplegia and tetraplegia of any cause be notified. That would bring us very soon, I think, over the difficulties we'have with national statistics.

I am very glad indeed that the Spinal Units on the Continent are now sharing their experiences, and I hope that this type of 'Common Market', to which Great Britain, Canada, the United States, Australia, Israel, South-Africa and Argentine, have made some essential contributions, may develop into a global one. 